\title{
TUMOR NEUROECTODÉRMICO MELANOCÍTICO DA INFÂNCIA (PROGONOMA): RELATO DE CASO ENFATIZANDO OS ASPECTOS TOMOGRÁFICOS E REVISÃO DA LITERATURA*
}

\author{
Cyrillo Rodrigues de Araújo Júnior ${ }^{1}$, Tarcísio Nunes Carvalho ${ }^{1}$, Sérgio Roberto Fraguas Filho ${ }^{1}$, \\ Marlos Augusto Bitencourt Costa ${ }^{1}$, Ana Olívia Cardoso Borba ${ }^{1}$, Sizenildo da Silva Figueirêdo ${ }^{1}$, \\ Márcio Martins Machado ${ }^{2}$, Kim-Ir-Sen Santos Teixeira ${ }^{3}$
}

\begin{abstract}
Resumo 0 tumor neuroectodérmico melanocítico da infância, também conhecido como progonoma, é uma enfermidade rara, benigna, originária da crista neural e que aparece no primeiro ano de vida, acometendo preferencialmente a maxila. Os autores relatam um caso raro deste tumor na maxila de uma criança de dez meses de idade, dando ênfase aos aspectos diagnósticos na tomografia computadorizada, e fazem uma revisão da literatura.

Unitermos: Neoplasia; Crista neural; Maxila; Infância; Tomografia computadorizada.
\end{abstract}

Abstract Melanotic neuroectodermal tumor of infancy (progonoma): a case report emphasizing the computed tomography findings and literature review.

The melanotic neuroectodermal tumor of infancy, also known as progonoma, is a rare benign disease of neural crest origin that occurs within the first year of life and affects mainly the maxilla. The authors report a case of a 10-month-old child presenting with this uncommon tumor in the maxilla, emphasizing the diagnostic findings on computed tomography, and present a literature review.

Key words: Neoplasia; Neural crest; Maxilla; Infancy; Computed tomography.

\section{INTRODUÇÃO}

Poucas neoplasias da cabeça e pescoço têm levantado tanta controvérsia quanto a sua origem como o tumor neuroectodérmico melanocítico da infância (TNMI). Este fato reflete a variedade de denominações que esta lesão recebeu no passado. Atualmente, a expressão tumor neuroectodémico melanocítico da infância tem sido largamente usada e aceita por descrever apropriadamente a lesão e a sua mais provável origem (crista neural). Desta forma, utilizaremos este nome durante todo o nosso artigo.

O objetivo deste trabalho se baseia em mostrar, de maneira clara e sucinta, os aspectos e achados diagnósticos relativos a este raro tumor, enfatizando o papel da to-

* Trabalho realizado no Serviço de Diagnóstico por Imagem do Hospital das Clínicas da Faculdade de Medicina da Universidade Federal de Goiás (HC-FMUFG), Goiânia, GO.

1. Médicos Residentes do Serviço de Diagnóstico por Imagem do HC-FMUFG.

2. Médico Cooperado do Serviço de Diagnóstico por Imagem do HC-FMUFG.

3. Professor Adjunto Doutor do Serviço de Diagnóstico por Imagem do HC-FMUFG.

Endereço para correspondência: Dr. Cyrillo Rodrigues de Araújo Júnior. Rua 7, ㄲo 1043, ap. 402, Setor Oeste. Goiânia, GO, 74110-090. E-mail: radiologia@brturbo.com

Recebido para publicação em 18/7/2003. Aceito, após revisão, em 5/1/2004. mografia computadorizada (TC) no seu diagnóstico, relatar mais um caso e realizar revisão da literatura atual vigente.

O TNMI usualmente se apresenta com crescimento rápido, localizado na região anterior da maxila de infantes, contudo, outros locais têm sido descritos na literatura. O tumor geralmente aparece dos três aos 12 meses de idade, sem predileção por sexo, e freqüentemente atrapalhando a amamentação.

Clinicamente se mostra como tumoração de contornos irregulares, coloração pardacenta, podendo conter dentes primários erupcionados prematuramente ou deslocados. Tem a consistência borrachosa e pode apresentar superfície ulcerada. Seu crescimento não produz rigidez, não tem pulsação e não apresenta produção de líquido, porém pode expandir a cortical adjacente e ter aparência radiográfica sugestiva de lesão maligna agressiva. Muitas vezes se observa reação periosteal do tipo em "raios de sol", o que nos leva a considerar o osteossarcoma como diagnóstico diferencial. Apesar deste aspecto agressivo, o TNMI é, na maioria das vezes, benigno, prontamente tratado por excisão conservadora; entretanto, existem raros relatos de comportamento maligno, tornando o acompanhamento pós-cirúrgico imprescindível.

\section{RELATO DO CASO}

Criança de dez meses de idade, do sexo feminino, foi encaminhada ao nosso Serviço para realização de TC, por apresentar lesão na face, de crescimento rápido, nos últimos quatro meses. A paciente apresentava-se em bom estado geral e moderadamente inquieta. Seu desenvolvimento neuropsicomotor era normal para a idade e não possuía história patológica pregressa significativa. Ao exame físico, notava-se abaulamento da região paranasal e do lábio superior esquerdo, e na avaliação intra-oral, lesão nodular, fixa, bem circunscrita, com mucosa adjacente preservada, de cor pardacenta, ocupando área de $2 \mathrm{~cm}$ na região anterior da maxila esquerda.

Radiografias periapicais revelaram área de rarefação óssea semelhante a cisto, anterior, na maxila esquerda, envolvendo e deslocando os germes dentários 61, 62 e 63. A hipótese de tumor odontogênico foi considerada.

Após avaliação clínica, foi solicitada e realizada TC com cortes de $2 \mathrm{~mm}$ de espessura e igual espaçamento, nos planos axial 
e coronal, sem e com o meio de contraste iodado, visando determinar a extensão da lesão e sua relação com as estruturas adjacentes. Verificou-se lesão estendendo-se da linha mediana da maxila até a região dos germes dentários 61, 62 e 63, ocupando os alvéolos correspondentes. $\mathrm{O}$ aspecto à TC era de processo expansivo, bem delimitado por fina camada óssea em toda a sua borda, com interior mostrando atenuação de partes moles realçando após administração de contraste. Os germes dentários adjacentes estavam deslocados medialmente (Figuras 1A e 1B). Algumas áreas hiperatenuantes irregulares de permeio foram vistas na região inferior da lesão (Figura 1C).

Nos cortes coronais, demonstrou-se melhor a sua localização na região ântero- medial da maxila esquerda (Figura 1D). A parede nasal lateral estava intacta, porém afilada. $\mathrm{O}$ assoalho da órbita não foi afetado. A biópsia incisional foi indicada, revelando tecido mole, de coloração pardacenta e consistência fibrosa. Os cortes microscópicos revelaram agregados de células contendo núcleos grandes e pálidos com citoplasmas claros e quantidade variável de pigmentos de hemossiderina em seu interior. Notavam-se, também, aglomerados de células com núcleos pequenos e basofílicos, arranjados ora em um padrão alveolar formando espaços revestidos por células tumorais pigmentadas, ora formando folhetos. De permeio, notava-se tecido conjuntivo fibroso bem colagenizado (Figuras 2 e 3 ).
O diagnóstico histológico foi, então, de TNMI, corroborado posteriormente pela imuno-histoquímica (Quadro 1). A lesão foi curetada sob anestesia geral e a ferida foi fechada por aproximação das bordas da mucosa. A maxila curou-se satisfatoriamente e não há, até o momento, sinal de recorrência do tumor, encontrando-se a paciente bem, no quarto mês de acompanhamento pós-cirúrgico.

\section{DISCUSSÃO}

O TNMI é uma neoplasia benigna rara da infância ${ }^{(\mathbf{1})}$, sem predileção por sexo ${ }^{(2)}$, com menos de 150 casos descritos na literatura. A maxila é a região mais acometida, sendo também encontrado em mandí-

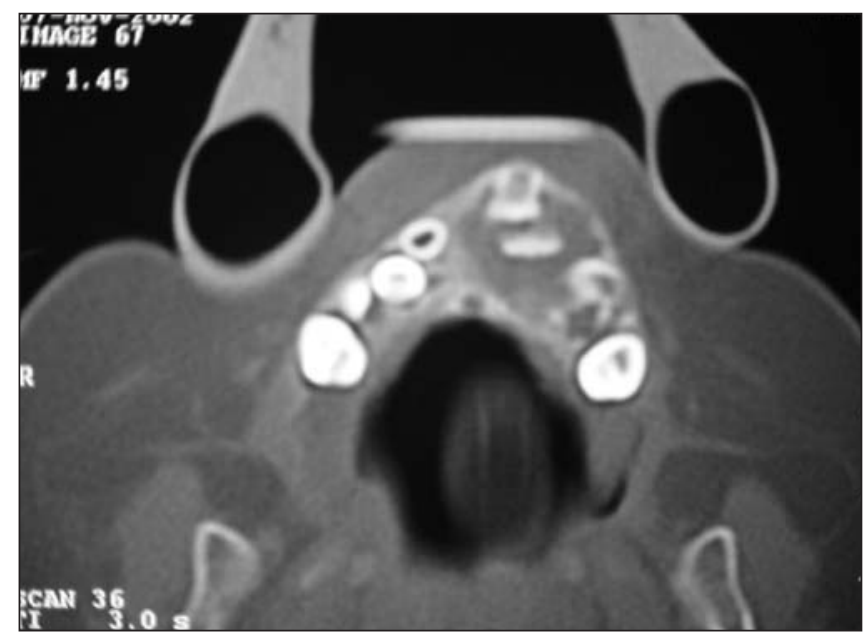

A

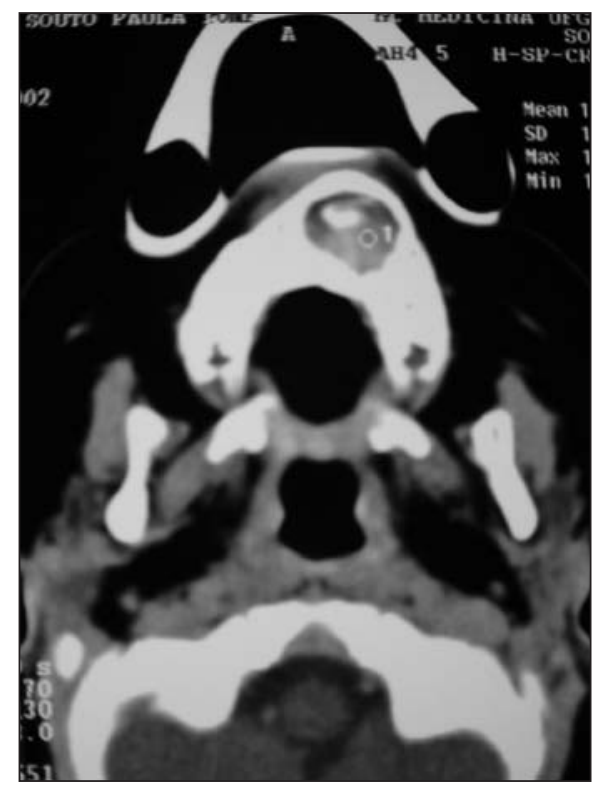

C

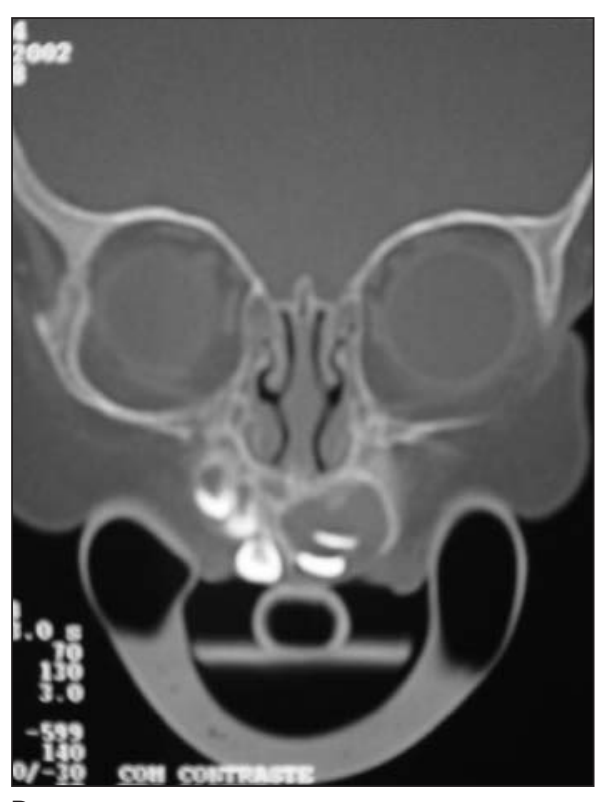

D

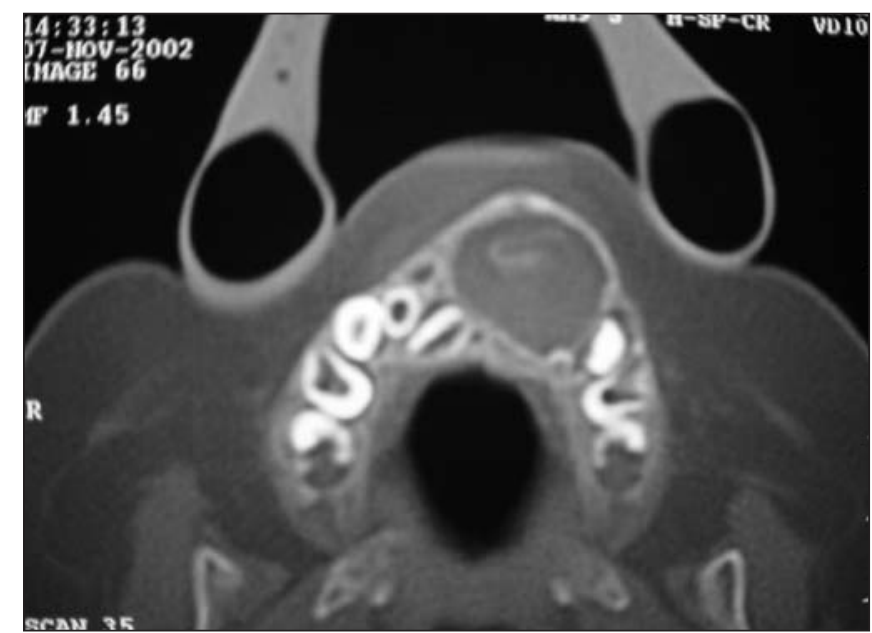

B

Figura 1. A,B: Corte axial de tomografia computadorizada, janela óssea, mostrando o aspecto insuflativo da lesão, delimitada por fina camada óssea e deslocando os germes dentários ântero-medialmente. Nota-se irregularidade de seu contorno na região póstero-inferior. C: Corte axial evidenciando atenuação de partes moles no interior da lesão. Houve realce após a administração do meio de contraste iodado. D: Corte coronal, janela óssea, mostrando a lesão localizada na região ântero-medial da maxila esquerda. 


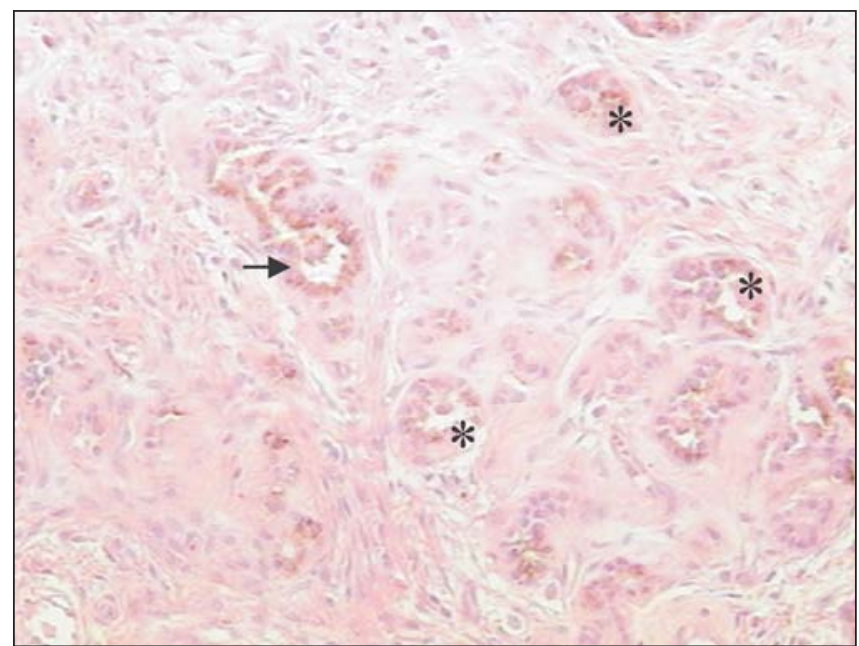

Figura 2. Presença de aglomerados de células redondas (asteriscos), algumas vezes formando padrão alveolar, com espaços revestidos por células pigmentadas (seta) (hematoxilina-eosina, aumento original 10x).

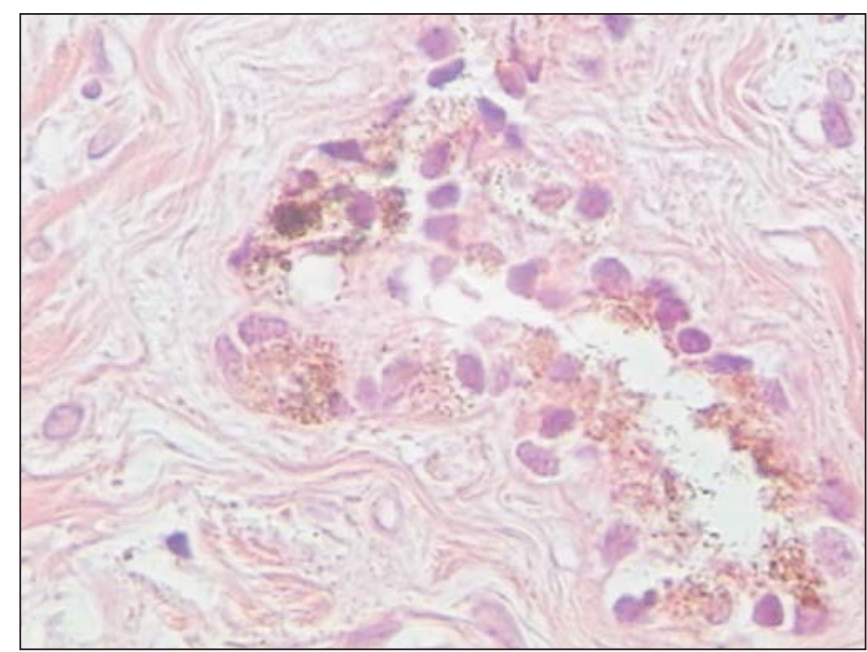

Figura 3. Fotomicroscopia ilustra um aglomerado de células tumorais contendo pigmentos compatíveis com melanina no interior dos citoplasmas (hematoxilina-eosina, aumento original $40 \times)$.
Quadro 1 Painel imuno-histoquímico.

\begin{tabular}{|l|l|}
\hline \multicolumn{1}{|c|}{ Painel de anticorpos } & Resultado \\
\hline $\begin{array}{l}\text { Proteína melanoma específica } \\
\text { (HMB-45) }\end{array}$ & Positivo \\
Produto de gene MIC-2 - CD-99 & \\
(12E7) & Positivo \\
Proteína S-100 (policlonal) & Positivo \\
Antígeno Ki-67 (KiS5) & Positivo* \\
Pancitoceratina (AE1/AE3) & Positivo \\
\hline
\end{tabular}

* Em raras células.

bula, crânio, cérebro, zigomático, ombro, mediastino, orofaringe e perna (Quadro $2)^{(2)}$. Quem primeiro descreveu esta entidade foi Krompecher ${ }^{(3)}$, em 1918, tendoa considerado variante do melanocarcinoma congênito. Desde então, várias denominações já foram usadas, em virtude da etiologia incerta desta neoplasia, como: odontoma epitelial melanocítico, progonoma melanocítico, adamantinoma pigmentado, ameloblastoma melanocítico, epúlide pigmentado congênito, melanoameloblastoma, tumor alange da retina, melanocitoma e TNMI. Esta lesão é benigna, porém pode manifestar grande agressividade local. Existem na literatura relatos de raros casos malignos com evolução fatal ${ }^{(\mathbf{4 , 5})}$.

O TNMI da nossa paciente teve várias características facilitando o diagnóstico: a presença de lesão pigmentada, elevando a gengiva, localizada na maxila, em criança com menos de um ano de idade. É importante ressaltar ser o achado isolado de melanina insuficiente para o diagnóstico de
Quadro 2 Localização do TNMI em 140 casos descritos na literatura.

\begin{tabular}{|l|r|c|}
\hline \multicolumn{1}{|c|}{ Localização } & Número & Porcentagem \\
\hline Maxila & 108 & $77,1 \%$ \\
Fontanela anterior & 13 & $9,3 \%$ \\
Mandíbula & 10 & $7,1 \%$ \\
Osso temporal & 3 & $2,1 \%$ \\
Osso occipital & 1 & $0,7 \%$ \\
Osso frontal & 1 & $0,7 \%$ \\
Orofaringe & 1 & $0,7 \%$ \\
Mediastino & 1 & $0,7 \%$ \\
Ombro & 1 & $0,7 \%$ \\
Não mencionado & 1 & $0,7 \%$ \\
\hline
\end{tabular}

TNMI, uma vez que o melanoma e o ameloblastoma também podem contê-la ${ }^{(6)}$.

Dentre os diagnósticos diferenciais, devemos considerar a osteomielite, lesões odontogênicas benignas, epúlide congênito, cisto dentígero, dermóide, granuloma eosinófilo, tumor de células gigantes, granuloma reparativo; pelo fato de a lesão apresentar crescimento rápido, muitas vezes sem limites precisos e reação periosteal espiculada à TC, assemelha-se a neoplasias malignas como osteossarcoma, sarcoma de Ewing, melanoma, linfoma, rabdomiossarcoma, metástase de neuroblastoma e retinoblastoma (Quadro 3) ${ }^{(2)}$.

Muitas hipóteses têm sido aventadas para explicar a origem deste tumor, porém recentes descobertas usando microscopia eletrônica, bioquímica e imuno-histoquímica revelam ser aquele originário das cé-
Quadro 3 Diagnósticos diferenciais do TNMI acometendo a maxila.

Lesões benignas
Cisto dentígero
Dermóide
Granuloma eosinófilo
Tumor de células gigantes
Granuloma reparativo
Ameloblastoma
Lesões malignas
Neuroblastoma
Osteossarcoma
Sarcoma de Ewing
Rabdomiossarcoma
Linfoma

lulas da crista neural. Outro dado importante é a presença de altos níveis de ácido vanilmandélico na urina destes pacientes ${ }^{(7)}$, os quais voltam ao normal após a retirada do tumor, sugerindo mais uma vez ser sua origem relacionada com a crista neural ${ }^{(8-11)}$. Na nossa paciente, não foi avaliado o nível do ácido vanilmandélico. Foi, contudo, utilizado o estudo imuno-histoquímico pela técnica da estreptoavidinabiotina-peroxidase, após adequada recuperação antigênica, corroborando a impressão diagnóstica de TNMI (Quadro 1).

Nagase et $_{\text {al. }}{ }^{(\mathbf{1 2})}$ acompanharam $17 \mathrm{ca}$ sos de TNMI recorrente e encontraram dois grupos diferentes: o primeiro apresentando lesão a distância, lobulada insuflativa, semelhante ao tumor primário, e o segundo apresentando infiltração tumoral difusa em osso trabeculado. Steinberg et al. ${ }^{(\mathbf{1 3})}$ 
relataram um caso de TNMI recorrente e propuseram que algumas formas deste tumor podem ser multicêntricas. Relatos mostram um potencial de malignização entre $1,9 \%$ e $3,2 \%$ e que, uma vez rompida a cortical óssea, o crescimento tumoral acelera ${ }^{(\mathbf{1 0 , 1 1})}$. A taxa de recorrência observada foi estimada em cerca de $15 \%{ }^{(2)}$.

Em todas as circunstâncias a TC se mostrou de auxílio inestimável para o diagnóstico e para o planejamento cirúrgico, definindo outros focos de lesão, sua extensão, contornos e composição. No nosso caso ela esclareceu a natureza benigna da lesão, mostrando ser insuflativa, homogênea, bem circunscrita e composta de material com atenuação de partes moles (Figura 1).

A TC fornece, ainda, informações sobre a multicentricidade da lesão, extensão e relação com as estruturas adjacentes como o seio maxilar, o nariz, a fossa infratemporal e a órbita. Por isso, devemos considerar a TC como uma ferramenta essencial para o diagnóstico e o planejamento cirúrgico, obtendo imagens nos planos axial e coronal, para uma melhor avaliação (Quadro 4) ${ }^{(2)}$. A ressonância magnética pode ser útil para avaliar a extensão tumoral e a invasão tecidual. O tumor é geralmente isointenso em T1 e levemente hiperintenso em T2, quando comparado ao tecido muscular.

\section{CONCLUSÃO}

Apresentamos um caso de TNMI com manifestações clínico-radiológicas muito
Quadro 4 Características radiográficas do TNMI acometendo a maxila.

- A TC revela tumor lítico, expansivo, na maxila, localmente invasivo e com hiperostose variável, apresentando massa de tecidos moles, homogênea, com realce vascular uniforme após injeção de contraste.

- A ressonância magnética pode ser útil para avaliar a extensão tumoral e a invasão tecidual. 0 tumor é isointenso em T1 e levemente hiperintenso em T2, quando comparado ao tecido muscular.

características. Esta entidade é rara, existindo escassas referências na literatura brasileira. A importância do reconhecimento radiográfico desta enfermidade e de seus possíveis diagnósticos diferenciais foram abordados.

Este caso ilustra bem a importância da TC para o correto diagnóstico e conduta apropriada. Foram discutidos, ainda, os últimos relatos da literatura sobre a etiopatogenia, os achados imuno-histoquímicos e os aspectos na TC desta neoplasia.

\section{Agradecimento}

Agradecemos à Dra. Aline Carvalho Batista, professora de patologia bucal da Faculdade de Odontologia da Universidade Federal de Goiás, por nos ter gentilmente oferecido as fotos das lâminas e o resultado da imuno-histoquímica.

\section{REFERÊNCIAS}

1. Blank E,Runckel DN. Case Report 119: melanotic neuroectodermal tumor of infancy (progonoma). Skeletal Radiol 1980;5:179-82.
2. Hupp JR, Topazian RG, Krutchkoff DJ. The melanotic neuroectodermal tumor of infancy. Report of two cases and review of the literature. Int J Oral Surg 1981;10:432-46.

3. Krompecher E. Zur histogenese und morphologie der adamantinome und sonstiger kierfergeschwülste. Beitr Path Anat 1918;64:165-97.

4. Block JC, Waite DE, Dehner LP, Leonard AS, Ogle RG, Gatto DJ. Pigmented neuroectodermal tumor of infancy. An example of rarely expressed malignant behavior. Oral Surg Oral Med Oral Pathol 1980;49:279-85.

5. Dehner LP, Sibley RK, Sauk JJ Jr, et al. Malignant melanotic neuroectodermal tumor of infancy: a clinical, pathologic, ultrastructural and tissue culture study. Cancer 1979;43:1389-410.

6. Cheung LK, Piette EMG, Tideman H. Melanotic neuroectodermal tumor of infancy: a case report emphasizing the importance of computed tomog raphy. Dentomaxillofac Radiol 1991;20:172-4.

7. Borello ED, Gorlin RJ. Melanotic neuroectodermal tumor of infancy - a neoplasm of neural crest origin: report of a case associated with high urinary excretion of vanilmandelic acid. Cancer 1966;19: 196-206.

8. Hahn JF, Sperber EE, Netsky MG. Melanotic neuroectodermal tumors of the brain and skull. J Neuropathol Exp Neurol 1976;35:508-19.

9. Nathanson NR, Tedeschi LG. Melanotic progonoma, a tumor of infancy. Oral Surg Oral Med Oral Pathol 1967;23:354-61.

10. Carpenter BF, Jimenez C, Robb IA. Melanotic neuroectodermic tumor of infancy. Pediatr Pathol 1985;3:227-44.

11. Cutler LS, Chaudhury AP, Topazian R. Melanotic neuroectodermal tumor of infancy: an ultrastructural study, literature review, and re-evaluation. Cancer 1981;48:257-70

12. Nagase M, Ueda K, Fukushima M, Nakajima T. Recurrent melanotic neuroectodermal tumour of infancy: case report and survey of 16 cases. J Maxillofac Surg 1983;11:131-6.

13. Steinberg B, Shuler C, Wilson S. Melanotic neuroectodermal tumor of infancy: evidence for multicentricity. Oral Surg Oral Med Oral Pathol 1988; 66:666-9. 